\title{
How can clinician-educator training programs be optimized to match clinician motivations and concerns?
}

\author{
Brendan McCullough \\ Gregory E Marton \\ Christopher J Ramnanan \\ Faculty of Medicine, University \\ of Ottawa, Ottawa, ON, Canada
}

\author{
This article was published in the following Dove Press journal: \\ Advances in Medical Education and Practice \\ 22 January 2015 \\ Number of times this article has been viewed
}

Background: Several medical schools have implemented programs aimed at supporting clinician-educators with formal mentoring, training, and experience in undergraduate medical teaching. However, consensus program design has yet to be established, and the effectiveness of these programs in terms of producing quality clinician-educator teaching remains unclear. The goal of this study was to review the literature to identify motivations and perceived barriers to clinician-educators, which in turn will improve clinician-educator training programs to better align with clinician-educator needs and concerns.

Methods: Review of medical education literature using the terms "attitudes", "motivations", "physicians", "teaching", and "undergraduate medical education" resulted in identification of key themes revealing the primary motivations and barriers involved in physicians teaching undergraduate medical students.

Results: A synthesis of articles revealed that physicians are primarily motivated to teach undergraduate students for intrinsic reasons. To a lesser extent, physicians are motivated to teach for extrinsic reasons, such as rewards or recognition. The key barriers deterring physicians from teaching medical students included: decreased productivity, lack of compensation, increased length of the working day, patient concerns/ethical issues, and lack of confidence in their own ability.

Conclusion: Our findings suggest that optimization of clinician-educator training programs should address, amongst other factors, time management concerns, appropriate academic recognition for teaching service, and confidence in teaching ability. Addressing these issues may increase the retention of clinicians who are active and proficient in medical education.

Keywords: clinician-educators, teaching, undergraduate medical education

\section{Introduction}

Developed by the Royal College of Physicians and Surgeons of Canada in 1996, the CanMEDS framework has served as the flagship document describing the characteristics and abilities required for a doctor to be fully competent and to provide the highest quality patient care. ${ }^{1}$ The CanMEDS-defined physician competencies now shape medical education and clinical medical training. One of the seven necessary roles of the physician described in this framework is that of a scholar who must demonstrate a lifelong commitment to learning in addition to the creation, dissemination, and translation of medical knowledge. Further, physicians must facilitate the education of their students, patients, and colleagues through active teaching. ${ }^{1}$ Clinician-educators range from clinicians who hold positions within academic institutions and have designated amounts of time devoted to education, to community-based physicians who mostly
Correspondence: Brendan McCullough Faculty of Medicine, University of Ottawa, 45I Smyth Road, Ottawa, ON KIH 8M5, Canada

Tel + I 6I3883670I

Email bmccu 104@uottawa.ca 
do clinical work and have students and residents join them in their practice. ${ }^{2}$

Despite the importance of teaching skills to clinicians, there remains a lack of consensus regarding the effectiveness of many teacher training programs at medical schools across North America as they may not fully address the needs of the individuals involved. ${ }^{3}$ MacDougall et al identified two areas critical in teacher development, ie, encouragement and motivation of teachers and constraints on teaching and learning. ${ }^{3}$ Similarly, Sturman et al found that general practitioners are likely to weigh the perceived rewards or benefits of practicebased undergraduate medical student teaching against the perceived costs and challenges in deciding whether to accept a student placement and how to approach teaching. ${ }^{4}$

The literature suggests that medical schools are finding it increasingly difficult to recruit and retain physicians willing to teach students and residents. ${ }^{5}$ A potential solution to this problem could be the development of formal clinicianeducator programs. ${ }^{6}$ As clinical skills teaching and patient interactions have extended into the preclerkship years, requiring greater commitments of clinician-educators in the undergraduate medical curriculum, numerous undergraduate medical school programs across Canada have begun to implement teaching programs aimed at providing select physicians with mentoring, development, and teaching opportunities in order to enhance their teaching skills. ${ }^{7}$ The value of these programs remains unclear, as to date, many of these programs have not been formally evaluated to ascertain their effectiveness in terms of producing or retaining quality clinicianeducators. ${ }^{8}$ In light of the uncertainty regarding the value of clinician-educator training programs, and considering the current lack of an appropriate consensus regarding what such a program should incorporate, we reviewed the literature to thoroughly characterize the motivations of physicians to teach undergraduate medical students and the barriers and challenges associated with teaching learners at this level. This synthesis would then be utilized to inform recommendations to optimize clinician-educator programs and produce higher quality clinician-educators in the future.

\section{Methodology}

In order to identify the motivations of physicians to teach undergraduate medical students, as well as to identify the challenges involved with doing so, the authors conducted a search of the PubMed database in June 2013 for papers meeting the following inclusion criteria: study participants were physicians in a teaching setting; study focused primarily on undergraduate medical education; study directly addressed the motivations of physicians to teach undergraduate medical students and/or barriers preventing them from doing so. Studies that focused primarily on the teaching of residents or fellows, those that were published prior to 1990, and those that were not published in English were excluded.

The MeSH terms "motivation", "attitude", "teaching","physician", "education, medical, undergraduate" were used for the initial search and "exploded" to include the terms "disincentives" and "barriers", and to exclude articles that had a focus on graduate medical education. In total, 203 results were produced. Thirty-seven articles remained after an exclusion process by title alone. After reading through the abstracts of the 37 articles, 16 were deemed relevant to the objective of the study and were read in detail. The references of the relevant articles were also manually searched, leading to a total of 37 papers. A further search with nonspecific engines such as Google Scholar and DogPile yielded one additional unique article for a total of 38 to be included in the review (refer to the Supplementary material). ${ }^{2,4,9-44}$

The primary objective of this review was to assess physicians teaching undergraduate medical students; therefore articles that focused primarily on the teaching of residents or fellows were excluded. Although there may be many similarities in physicians' motivations to teach undergraduate medical students and those of a higher level of training, there are sufficient differences to warrant excluding articles of this nature. For example, the literature has suggested that physicians may have different motivations for teaching residents and fellows, such as increased call shift coverage and more efficient clinics. ${ }^{34,45}$ Articles that did not specify the stage of training of the learners but simply used the term "medical students" were included as it was felt that these articles would still hold valuable information pertaining to the motivations of physicians to teach or barriers preventing them from doing so.

\section{Results}

Two coders worked independently using open coding to review the 38 selected articles and identify themes related to the motivations of physicians to teach undergraduate medical students or to the perceived barriers limiting participation in undergraduate medical teaching. These themes were not preconceived by the coders, but rather emerged from review of the literature. Through consensus, the coders developed the list of themes outlined in Table 1. Two subthemes identified under the overarching "motivations" theme were "intrinsic motivations" and "extrinsic motivations". Intrinsic motivation refers to motivation that is driven by an interest or enjoyment 
Table I Summary of motivations and barriers identified in literature review

\begin{tabular}{|c|c|c|}
\hline & Proportion of reviewed articles & Examples \\
\hline \multicolumn{3}{|l|}{ Motivations } \\
\hline Intrinsic motivations & $29 / 38(76 \%)$ & $\begin{array}{l}\text { - Enjoyment in observing outcomes of teaching } \\
\text { - Appreciation for new perspectives gained from students } \\
\text { - Sense of duty } \\
\text { - Self-reflection on own skills }\end{array}$ \\
\hline Extrinsic motivations & $15 / 38$ (39\%) & $\begin{array}{l}\text { - Financial compensation } \\
\text { - Teaching awards } \\
\text { - University appointments } \\
\text { - Teaching workshops }\end{array}$ \\
\hline \multicolumn{3}{|l|}{ Barriers/challenges } \\
\hline Decreased productivity & $17 / 38(45 \%)$ & $\begin{array}{l}\text { - Lack of time to work with students } \\
\text { - Increased pressure to generate salary through patient care instead of teaching } \\
\text { - Presence of students had negative impact on patient flow in practice } \\
\text { - Fewer patients seen per day }\end{array}$ \\
\hline Increased length of day & $8 / 38(21 \%)$ & $\begin{array}{l}\text { - Work took longer to complete in presence of students } \\
\text { - Average length of day increased between } 46 \text { and } 51 \text { minutes }\end{array}$ \\
\hline Lack of compensation & $10 / 38(26 \%)$ & $\begin{array}{l}\text { - Level of pay inadequate for time commitment involved } \\
\text { - Presence of medical students leads to fewer patients seen and subsequent loss } \\
\text { of income from lack of billing } \\
\text { - Many institutions do not reward financially }\end{array}$ \\
\hline $\begin{array}{l}\text { Patient concerns/ethical } \\
\text { issues }\end{array}$ & $9 / 38(24 \%)$ & $\begin{array}{l}\text { - Patients may be reluctant to divulge information in presence of student } \\
\text { - Students may have poor attitudes that negatively impact patient care } \\
\text { - Incompetent medical students may put patients at risk }\end{array}$ \\
\hline $\begin{array}{l}\text { Lack of clinician-educator } \\
\text { confidence }\end{array}$ & $9 / 38(24 \%)$ & $\begin{array}{l}\text { - Physician "short-cuts" in physical exam were not appropriate for students to learn } \\
\text { - Feelings that clinical knowledge is too inadequate to teach } \\
\text { - Lack of support from practice partners to teach } \\
\text { - Perceived lack of training as a teacher }\end{array}$ \\
\hline
\end{tabular}

in the task itself, and exists within the individual rather than relying on external pressures or a desire for reward. ${ }^{46}$ Extrinsic motivation refers to the performance of an activity in order to attain an outcome, and comes from outside of the individual ${ }^{44}$ Common extrinsic motivations are rewards (eg, money) for showing a desired behavior, or the threat of punishment following misbehavior. ${ }^{47}$ Additionally, major subthemes identified under the "barriers/challenges" theme were "decreased productivity", "lack of compensation", "increased length of day", "patient concerns/ethical issues", and "lack of clinician-educator confidence".

\section{Motivations/rewards}

Intrinsic motivations

In 29 of the 38 studies reviewed (76\%), physicians cited some sort of "intrinsic motivation" as one of their main reasons for teaching undergraduate students., ${ }^{2,49-35}$ For example, Gerrity et al indicated that physicians enjoyed observing the outcomes of their teaching and the opportunity to share the satisfaction derived from patient care with students. Physicians also appreciated the new perspectives obtained from instructing students during patient interactions, giving them the opportunity to reflect on their own skills. ${ }^{2}$ Similarly, Hartley et al found that physicians valued the presence of students, as it increased the time of their clinical encounters, enhanced their teaching skills, and improved the overall image of their practice in the eyes of patients. ${ }^{14}$ Other studies concluded that physicians who taught medical students had a strong desire to improve medical education and felt that they had a duty to give back to the medical community. ${ }^{21,22}$ Finally, it was found that the number of these intrinsic incentives present increased as the level of training of the medical student increased. ${ }^{34}$

\section{Extrinsic motivations}

In 15 of the 38 studies reviewed (39\%), physicians reported having "extrinsic motivations" to teach undergraduate medical students., ${ }^{9} 10,12,17-21,27-29,36-39$ In one particular study, physicians stated that even meager financial reimbursement increased their accountability toward students and made them more likely to continue future teaching. ${ }^{9}$ Conversely, many of these physicians were more likely to stop serving as preceptors if students evaluated them negatively. In this same study, the majority of physicians felt that everyone should be rewarded or recognized for teaching, while outstanding 
teachers should be given additional recognition. ${ }^{9}$ Physicians in multiple other studies also agreed that rewards or recognition for teaching were highly desirable. ${ }^{17,18,27-29,36}$ In other articles reviewed, it was found that physicians valued the opportunity to improve their teaching skills or to receive additional training in a particular area of medical education. ${ }^{17,36}$ For many other physicians, simply having regular contact or affiliation with a university was incentive enough to be involved in teaching, ${ }^{12,21}$

\section{Barriers/challenges Decreased productivity}

In 17 of the 38 studies reviewed (45\%), physicians reported that they simply did not have time to teach or that medical students somehow affected their daily productivity. 2,9,11,13-15,20-23,29,31-33,36,39,40 Gray et al found that $90.7 \%$ of general practitioners surveyed cited a lack of time as a major factor preventing or discouraging them from teaching medical students in their office. ${ }^{13}$ Borges et al identified that there is often increased pressure on academic physicians to generate more of their salary through patient care, reducing time for research and/or teaching. ${ }^{40}$ Multiple other studies reported that the presence of medical students had a negative impact on patient flow. ${ }^{20,23,29,32,36,39}$ For example, physicians in one study saw an average of 1.4 fewer patients per day with students present. ${ }^{20}$

\section{Increased length of day}

In eight of the 38 studies reviewed (21\%), physicians reported that while a student was present, their work took longer to complete or the length of their average day was increased. 2,9,10,15,20,32,39,43 According to a study by Vinson et al, teachers noted a 30-minute (median) lengthening of their workday with students present, while Baldor et al reported increases of up to 60 minutes., ${ }^{9,32}$ Other studies showed average increases of 46-51 minutes per day. ${ }^{20,41}$

\section{Lack of compensation}

In ten of the 38 studies examined (26\%), physicians reported either a lack of compensation or a loss of potential income as a major barrier preventing them from teaching. ${ }^{10,13,20,23,29,32-34,39,43}$ Wilson et al reported that $89 \%$ of physicians surveyed in their study felt that present levels of remuneration for teaching were inadequate for the time commitment involved. ${ }^{33}$ In another study conducted by Vinson et al, only $9 \%$ of physicians surveyed reported being paid at all. ${ }^{32}$ Multiple other sources pointed to the fact that the presence of medical students in a private practice or clinic often leads to fewer patients being seen and therefore a loss of income from lack of billing. ${ }^{20,23,29,39}$ Lastly, Woolliscroft et al concluded that while many institutions tend to provide supportive teaching environments, many do not reward teaching financially. ${ }^{34}$

\section{Patient concerns/ethical issues}

In nine of the 38 studies reviewed (24\%), physicians expressed concern either about the well-being of their patients while students were present, or patients being reluctant to divulge pertinent information in the presence of a learner. These studies also highlighted traits and characteristics of students that had a potential impact on patient care. . $^{2,410,13,15,16,19,40,44}$ According to Sturman et al, many students had unsatisfactory or insufficient levels of knowledge, interest, competence, and/or professionalism that made teaching difficult. ${ }^{4}$ Another study found that medical educators might encounter students with inappropriate attitudes toward those of a different race, ethnicity, or gender. ${ }^{44}$ These students could potentially be detrimental to a medical practice by making patients feel uncomfortable and by failing to provide impartial care. For example, one study cited that physicians are often concerned that patients may not disclose all facts relevant to a diagnosis in the presence of a learner and hence may receive inadequate treatment. ${ }^{2}$ Other studies have found that physicians often have difficulty recruiting patients who will even agree to see medical students, let alone agree to provide information. ${ }^{4,15}$

\section{Lack of clinician-educator confidence}

In nine of the 38 studies reviewed (24\%), physicians communicated that they were often hesitant to get involved in teaching because they lacked confidence in their own ability to do so. Some of these studies also alluded to the fact that physicians may often feel unsupported by their partners to have students present in a teaching capacity. $2,13,15,22,24,32,33,40,42$ In an article by Gray et al, 34\% of 303 physicians surveyed reported that they had a lack of confidence in their own medical knowledge. ${ }^{13}$ Another study by Hartley et al revealed that many physicians might have anxiety about the adequacy of their teaching. In other words, these physicians thought that "short cuts" in their clinical examinations of patients were not appropriate for students to learn. ${ }^{15}$ One study indicated that there may also be gender differences in level of teaching confidence, with male doctors feeling more confident about certain clinical teaching skills relative to their female peers. ${ }^{24}$ Further evidence points to the possibility that physicians may lack confidence in teaching, or simply choose not to teach, due to a lack of teacher training. Vinson et al noted that twice as many medical teachers had received at least 
some training in how to teach medical students relative to clinicians not active in medical teaching. ${ }^{32}$ Of the physicians who reported some teacher training, $79 \%$ had received 2 days or less training. ${ }^{32}$ Lastly, physicians may lack the confidence to teach a particular area of medicine that falls out of their area of expertise. In a study of general practitioners teaching psychiatry to medical students, Thompson et al found that many of these physicians were not confident in their abilities to competently cover all areas of the subject. ${ }^{42}$

\section{Discussion}

Several undergraduate medical school programs within Canada have initiated teaching programs aimed at providing physicians with mentoring, workshops, and teaching opportunities in order to enhance their skills in an educational setting. ${ }^{48}$ Currently it is difficult to assess the effectiveness of these programs on a national level, as assessments of clinician-educators are variable across institutions. Further, it has been suggested that, in roughly half of the faculties of medicine in Canada, there is no uniform system for providing assessment results to clinician-educators, thereby giving them no formal way to improve their performance. ${ }^{8}$ Taking this information into account, the purpose of this review was to analyze the motivations and challenges experienced by clinician-educators in an undergraduate medical education setting in order to inform the development of clinician-educator training programs across Canada. In 2008, the Association of Faculties of Medicine of Canada (AFMC) conducted an extensive study looking at the complex relationship between clinician-educators and faculties of medicine, universities, medical associations, and governments across Canada. ${ }^{8}$ This discussion incorporates many of the recommendations derived from the AFMC document as well those proposed in the most recent literature up to June 2013. Please refer to Table 2 for a full summary of recommendations identified.

\section{Intrinsic motivations}

Our review of the literature suggests that the vast majority of physicians who teach undergraduate medical students pursue these teaching activities due to intrinsic motivations.

Table 2 Summary of recommendations addressing motivations and barriers experienced by physicians

\begin{tabular}{|c|c|}
\hline & Recommendations \\
\hline \multicolumn{2}{|l|}{ Motivations } \\
\hline Intrinsic motivations & $\begin{array}{l}\text { - Program developers may want to consider promoting the rewards of teaching and remind physicians that } \\
\text { they have a unique opportunity to inspire students and help influence the future of patient care }\end{array}$ \\
\hline Extrinsic motivations & $\begin{array}{l}\text { - Have teaching contributions systematically recorded and compiled in a teaching portfolio or departmental } \\
\text { database } \\
\text { - Involve clinical-educators in curriculum development and educational policy } \\
\text { - Compensate physicians for lost time/income as a result of teaching }\end{array}$ \\
\hline \multicolumn{2}{|l|}{ Barriers/challenges } \\
\hline $\begin{array}{l}\text { Decreased productivity/increased } \\
\text { length of day }\end{array}$ & $\begin{array}{l}\text { - Reduce average daily patient list sizes to allow for protected teaching time } \\
\text { - Compensate physicians for lost time/reduced list sizes } \\
\text { - Give physicians significant advance notice of dates when students will be present, allowing them to alter their } \\
\text { schedules and notify their staff if necessary }\end{array}$ \\
\hline Lack of compensation & $\begin{array}{l}\text { - Five major elements that are seen as essential to have in a faculty teaching program in order to establish } \\
\text { equitable salaries for all physicians involved: accepted standards of adequate performance; systematic review } \\
\text { of the performance of academic staff; mechanisms for rewarding excellence; structured and effective means } \\
\text { of providing assistance to those whose performance is suboptimal; and options for sanctions against those } \\
\text { whose performance is consistently suboptimal }{ }^{8}\end{array}$ \\
\hline Patient concerns/ethical issues & $\begin{array}{l}\text { - Identify the student before seeking patient consent for teaching } \\
\text { - Ask the student to seek patient consent } \\
\text { - Physician can model the skill of seeking consent in difficult circumstances } \\
\text { - Physician should always maintain patient confidentiality in teaching consultations of sensitive information } \\
\text { - Students should be given clear instructions as to appropriate behavior prior to commencing a clinical placement } \\
\text { - Student expectations and responsibilities should be made clear prior to commencing a placement }\end{array}$ \\
\hline $\begin{array}{l}\text { Lack of clinician-educator } \\
\text { confidence }\end{array}$ & $\begin{array}{l}\text { - Physicians should be granted ample opportunity to increase their skills as teachers, lecturers, coaches, } \\
\text { mentors, and evaluators regardless of whether they are in a tertiary medical center or in the community } \\
\text { - In order to continue improving or meet a certain standard, clinician-educators need feedback on the } \\
\text { effectiveness of their teaching coupled with opportunities to improve in areas of weakness } \\
\text { - Universities should make expected teaching contributions clear at least a year in advance } \\
\text { - Teacher training should not simply be an option for select clinician-educators looking to improve their skills, } \\
\text { but rather a requirement for all those with regular teaching duties }\end{array}$ \\
\hline
\end{tabular}

Note: Data from Cook D. Study of Clinical Teachers in Canadian Faculties of Medicine. The Association of Faculties of Medicine of Canada; 2009. Available from: https:// www.afmc.ca/pdf/Study\%20of\%20Clinical\%20Teachers\%20-\%20Discussion\%20Paper.pdf. Accessed October II, 20I4. ${ }^{8}$ 
Most physicians found undergraduate medical teaching rewarding and enjoyable and gained great satisfaction from contributing to medical education and improving the skills and knowledge of their learners. Those looking to develop or modify an existing clinician-educator program at their institution should recognize that facilitating the professional growth, development, and satisfaction of clinician-educators could promote their recruitment or retention. ${ }^{14}$ One could argue that the well-being of a physician is enhanced by the extent to which they find meaning in their work, therefore highlighting that the intrinsic rewards associated with teaching could be a key element to producing motivated and fulfilled clinician-educators in the future. ${ }^{28}$

\section{Extrinsic motivations}

Several studies have indicated that extrinsic motivations drive physicians to participate in undergraduate medical teaching. These motivations most often included financial reimbursement, teaching awards, recognition for teaching contribution, opportunity to improve teaching skills, and university affiliation or faculty appointment. Logically, there is a possibility that incorporation of all these elements into the development or modification of a faculty-teaching program would serve to augment the recruitment or retention of clinician-educators. Gerrity et al highlighted the fact that giving teachers (particularly those based in the community) faculty appointments provides recognition of their work and indicates that they are part of an academic community and integral to the school's overall efforts. In order to ensure that all teachers truly get the recognition that they deserve, it would be beneficial to have teaching contributions systematically recorded and compiled in a faculty-recognized teaching portfolio or departmental database. ${ }^{2}$ Through this method, all teachers would receive credit for their involvement and those with outstanding records could potentially be made eligible for teaching rewards.

Further, evidence has shown that clinician-educators value the opportunity to be involved in curriculum development and educational policy. ${ }^{11,21}$ It is possible that increased involvement in this regard could lead to more active participation in teaching, strengthen the development of teaching programs, and signal to physicians that they are in a partnership with the faculty based on mutual respect. ${ }^{2}$ Finally, the literature has revealed that monetary payment, whether as a modest honorarium or as compensation for lost time/income, was felt to be important for a large number of physicians. ${ }^{9}$ In a survey of 338 clerkship administrators from 77 American and ten Canadian medical schools, it was found that only $13 \%-22 \%$ of programs offered monetary payment to nonsalaried faculty for office-based teaching. Although other nonmonetary rewards like educational opportunities were offered by $70 \%-89 \%$ of the programs surveyed, it is important to keep in mind that financial compensation is still highly valued by physicians, so developers of clinicianeducator programs should strive to keep this in mind when creating their initial frameworks. ${ }^{37}$

\section{Decreased productivity/increased length of working day}

A large number of studies examined in this review indicated that physicians tend to see fewer patients in the presence of learners, and clinician-educators may be subject to an increased length of their working day. There is evidence that many fields of medicine, including general practice, are not only becoming busier, but that the people seen are more severely ill than in the past. Many teaching practices have experienced difficulty adjusting to this increased clinical service load while at the same time maintaining a high standard of undergraduate clinical teaching. Justifiably, many practices have opted to maintain the same patient volume, often sacrificing student teaching altogether, while others continue to struggle under increasing pressures to deliver both. ${ }^{33}$ With the increasing burden of patient care, there must be major changes to the structure of medical practices and specialty clinics if they are to be able to provide both quality care and valuable undergraduate teaching without undue time pressures. Possible suggestions include reducing average daily patient list sizes to allow for protected teaching time. In order to do this, faculties of medicine would need to subsidize teachers for a reduction in patient-derived income. Community preceptors affiliated with the Faculty of Medicine, University of British Columbia, receive a number of awards for having students in their offices. These include a clinical faculty appointment, 5 web hours per month on a university server, a library card for the university libraries, and $\$ 80$ per afternoon (approximate income lost for seeing two to three fewer patients). ${ }^{26}$ In order to further assist teachers in a community-based practice or hospital clinic, faculties of medicine can take steps such as reducing the amount of paperwork related to teaching as well as giving physicians significant advance notice of dates when students will be present. This will allow them to alter their schedules if necessary and to inform the rest of the staff in their practice about the presence of the student learner. ${ }^{2}$

\section{Lack of compensation}

Several articles indicated that either a lack of compensation or a loss of potential income serves as a major barrier 
preventing physicians from teaching. It was discovered in the 2008 AFMC study, based on the testimonies of over 200 key informants, that policies governing remuneration for clinician-educators varied widely between faculties, departments, and, between individual teachers. ${ }^{8}$ As a result, one could find teachers in a select department receiving no compensation for their contributions, while others in the same department had income from multiple sources. When clinician-educators did receive remuneration, it was most often in the form of a yearly salary ranging from under $\$ 500$ to over $\$ 150,000 .{ }^{8}$ The issue remains that currently there is no standardized system for determining salary and promotion decisions for clinicianeducators across Canada, leaving many dissatisfied with their level of remuneration. Through their study, the AFMC identified five major elements that were seen as essential to have in a faculty teaching program in order to establish equitable salaries for all physicians involved: accepted standards of adequate performance; systematic review of the performance of academic staff; mechanisms for rewarding excellence; structured and effective means of providing assistance to those whose performance is suboptimal; and options for sanctions against those whose performance is consistently suboptimal. ${ }^{8}$ If all of these elements were to be implemented on a national level, it is possible that we would see greater clinician-educator satisfaction as well as higher retention in undergraduate medical education.

\section{Patient concerns/ethical issues}

In a number of studies examined in this review, physicians expressed concern either about the well-being of their patients while students were present or about patients being reluctant to divulge pertinent information in the presence of a learner. In many of these studies, physicians also felt that students who were underprepared or who had poor attitudes adversely affected the practice or clinic. In the case of patients being reluctant to meet with students, there are numerous steps that a clinician-educator can take. First of all, it is helpful to identify the student before seeking patient consent for teaching, or ask the student to seek patient consent. Secondly, for the benefit of the student, the physician can model the skill of seeking consent in difficult circumstances. Lastly, it is important for a physician to always maintain patient confidentiality during encounters when a learner is present, especially if that patient had previously revealed sensitive information. ${ }^{41}$ Of course, there will always be patients who will refuse consent or will later regret having consented, and this is completely out of the hands of the clinician-educator or student learner. Future or current clinician-educator programs should provide specific training to deal with the aforementioned issues.

In order to minimize issues with student attitudes or lack of preparation during a clinical encounter, students should be given clear instructions as to appropriate behavior in this setting and what will expected of them. Further, they should be given guidance regarding ways to make the experience more rewarding for themselves and teachers. ${ }^{8}$ Clinician-educators on the other hand, need more practical information on course goals and objectives, expectations of students' performance, and the type of feedback students require and would value at their level of training. ${ }^{2}$

\section{Lack of clinician-educator confidence}

In numerous articles reviewed in this paper, physicians communicated that they lacked confidence in their ability to teach undergraduate medical students effectively. Gerrity et al speculated that a physician's long-term satisfaction is a direct function of how well they feel they do their job. As such, physicians should be given ample opportunity to increase their skills as teachers, lecturers, coaches, mentors, and evaluators regardless of whether they are in a tertiary medical center or in the community. Also, in order to continue improving or to meet a certain standard, clinician-educators need feedback on the effectiveness of their teaching coupled with opportunities to improve in areas of weakness. Most often, this feedback is more effective when received from peers. ${ }^{2}$

In order for clinical-educators to be adequately prepared for their teaching duties and hence have confidence in the subject matter and their ability to convey it, universities should make expected teaching contributions clear at least a year in advance. This will allow physicians, even those uncomfortable with a certain subject matter, time to prepare adequately. ${ }^{8}$ Learning and teaching is a lifelong process, so for those looking to create a faculty development program, teacher training should not simply be an option for select clinician-educators looking to improve their skills, but rather a requirement for all those with regular teaching duties. Even veteran clinician-educators with a wealth of experience should be required to take refresher courses so that they may utilize the most up-to-date and effective methods to instruct the future generation of health professionals. ${ }^{8}$

One question that arose from this paper is what medical schools with clinician-educator programs have done to either address the barriers preventing physicians from teaching or to promote the benefits of doing so. The Medical Education Scholars Program (MESP) was established at the University 
of Michigan Medical School in 1998 to develop educational leadership, improve teaching skills, and promote educational scholarship among medical school faculty. ${ }^{49}$ The program involves an active learning format where participants meet for 3.5 hours per week and discuss topics such as principles and theories of education, teaching methods, educational research methods, assessment and evaluation, and educational leadership. This program has seen a degree of success as participants have showed increases in number of promotions, number of educational responsibilities, and number of leadership positions held. However, the MESP has continued to struggle since its inception with establishing protected time for physicians to participate in teaching training/activities as well as securing funding to support participants financially. To tackle at least the former issue, the MESP has considered opening the program to health care professionals other than physicians so that funding for the program can be provided from sources other than the University of Michigan Medical School. ${ }^{49}$ The Medical College of Wisconsin also created a faculty development program in 1991 to give primary care physicians competency in providing medical education, research, writing, and use of technology. ${ }^{50}$ This program also utilized an active learning model, with physicians meeting 1.5 days per month over a 2-year period to complete the program. This program saw similar outcomes to the MESP, with participants showing continued involvement in medical education and taking on more clinical and leadership positions. This program also struggled with a lack of resources and found that there were great constraints placed on physicians' time due to their clinical duties. In order to remedy this, they reduced the format of the program to one half-day per month for a 4-5-month period to focus on a single educational topic. This allowed greater physician participation and a subsequent increase in teaching capabilities.

Other medical schools have taken more novel approaches to highlight the benefits of teaching and to motivate physicians to enter a career in medical education in the future. Numerous schools in the USA have implemented clinicianeducator track residency programs that allow residents in their final years to develop proficiency in teaching, curriculum development, and leadership. ${ }^{51,52}$ These programs have proven to be successful in improving the confidence of residents in their teaching abilities and also increase the likelihood that a resident will remain in medical education after graduation. ${ }^{51}$ Other schools have taken a step further and implemented peer-teaching programs at the undergraduate medical student level. These programs have been shown to improve participant confidence in teaching and may encourage students to enter medical education in their future careers. ${ }^{53-55}$

\section{Limitations}

Our review was limited by the fact that although many medical schools have developed clinician-educator programs, many have not published their program framework for critical appraisal. Further, many schools have not formally evaluated their programs in terms of producing competent and satisfied teachers. Our review was therefore unable to determine what proportion of clinician-educator programs are aware of the barriers/motivations involved in teaching undergraduate medical students and are actively taking measures to address them.

\section{Conclusion}

In order to optimize their effectiveness in terms of producing quality clinician-educators, clinician-educator programs first need to highlight the motivations of physicians who teach and the rewards associated with doing so, as well as address the barriers that prevent others from becoming involved in teaching. Program developers should strive to emphasize the intrinsic rewards of teaching, as well as aim to give teachers proper recognition for teaching contributions made. In order to address certain barriers to teaching, clinician-educators should be given adequate advance notice of teaching commitments, and faculties should attempt to implement a system for equitable compensation based on teaching performance and remediation for those who are subpar. Further, teacher training should not simply be an option for selection of clinician-educators looking to improve their skills, but rather a requirement for all those with regular teaching duties in undergraduate medical education. By following the specific recommendations discussed in this review, it is possible that new or existing clinician-educator programs could have higher teacher recruitment or retention rates and ultimately produce high-caliber, satisfied, and fulfilled clinician-educators.

\section{Disclosure}

The authors have no actual or potential conflicts of interest in relation to this paper.

\section{References}

1. Frank JR, editor. The CanMEDS 2005 Physician Competency Framework. The Royal College of Physicians and Surgeons; 2005. Available from: http://www.royalcollege.ca/portal/page/portal/rc/common/documents/ canmeds/resources/publications/framework_full_e.pdf. Accessed October 11, 2014.

2. Gerrity MS, Pathman DE, Linzer M, et al. Career satisfaction and clinician-educators. J Gen Intern Med. 1997;12(S2):S90-S97. 
3. MacDougall J, Drummond MJ. The development of medical teachers: an enquiry into the learning histories of 10 experienced medical teachers. Med Educ. 2005;39(12):1213-1220.

4. Sturman N, Régo P, Dick M-L. Rewards, costs and challenges: the general practitioner's experience of teaching medical students. Med Educ. 2011;45(7):722-730.

5. Quirk ME, Haley H-L, Hatem D, Starr S, Philbin M. Primary care renewal: regional faculty development and organizational change. Fam Med. 2005;37(3):211-218.

6. Kubiak NT, Guidot DM, Trimm RF, Kamen DL, Roman J. Recruitment and retention in academic medicine - what junior faculty and trainees want department chairs to know. Am J Med Sci. 2012;344(1):24-27.

7. thinkOttawaMedicine.ca. Department of Medicine physicians selected for distinguished teacher program. Available from: http:// thinkottawamedicine.ca/2011/03/department-of-medicine-physiciansselected-for-distinguished-teacher-program/. Accessed September 9 , 2014.

8. Cook D. Study of Clinical Teachers in Canadian Faculties of Medicine. The Association of Faculties of Medicine of Canada; 2009. Available from: https://www.afmc.ca/pdf/Study\%20of\%20Clinical\%20 Teachers\%20-\%20Discussion\%20Paper.pdf. Accessed October 11, 2014.

9. Baldor RA, Brooks WB, Warfield ME, O’Shea K. A survey of primary care physicians' perceptions and needs regarding the precepting of medical students in their offices. Med Educ. 2001;35(8):789-795.

10. Brennand EA, Hanson J, de Gara CJ. Faculty attitudes towards undergraduate medical education. University of Alberta Health Sciences Journal. 2006;3(1):9-15.

11. Dahlstrom J, Dorai-Raj A, McGill D, Owen C, Tymms K, Watson DA. What motivates senior clinicians to teach medical students? BMC Med Educ. 2005;5:27.

12. Fulkerson PK, Wang-Cheng R. Community-based faculty: motivation and rewards. Fam Med. 1997;29(2):105-107.

13. Gray J, Fine B. General practitioner teaching in the community: a study of their teaching experience and interest in undergraduate teaching in the future. Br J Gen Pract. 1997;47(423):623-626.

14. Grayson MS, Klein M, Lugo J, Visintainer P. Benefits and costs to community-based physicians teaching primary care to medical students. J Gen Intern Med. 1998;13(7):485-488

15. Hartley S, MacFarlane F, Gantley M, Murray E. Influence on general practitioners of teaching undergraduates: qualitative study of London general practitioner teachers. BMJ. 1999;319(7218):1168-1171.

16. Hill N, Wolf KN, Bossetti B, Saddam A. Preceptor appraisals of rewards and student preparedness in the clinical setting. JAllied Health. 1999;28(2):86-90.

17. Hoban J, Cariaga-Lo L, Bennet B, Ernest JM, Vanderweide SA, Harrington ME. Incentives for teaching. Acad Med. 1996;71(1): 106-107.

18. Kumar A, Kallen DJ, Mathew T. Volunteer faculty: what rewards or incentives do they prefer? Teach Learn Med. 2002;14(2):119-123.

19. Latessa R, Beaty N, Landis S, Colvin G, Janes C. The satisfaction, motivation, and future of community preceptors: the North Carolina experience. Acad Med. 2007;82(7):698-703.

20. Levy BT, Gjerde CL, Albrecht LA. The effects of precepting on and the support desired by community-based preceptors in Iowa. Acad Med. 1997;72(5):382-384.

21. May M, Mand P, Biertz F, Hummers-Pradier E, Kruschinski C. A survey to assess family physicians' motivation to teach undergraduates in their practices. PLoS One. 2012;7(9):e45846.

22. Molodysky E, Bunker J, Lee C, Sekelja N. Clinical teaching and clinical teacher training - GPs' attitudes and involvement. Aust Fam Physician. 2006;35(12):1006.

23. Moorhead R, Brett T, Arnold-Reed D, Saldanha M. General practice teachers. Med Teach. 2012;34(1):84-85.

24. Prichard D, Collins N, Boohan M, Wall C. Junior doctors and undergraduate teaching: the influence of gender on the provision of medical education. Teach Learn Med. 2011;23(2):155-160.
25. Rutter H, Herzberg J, Paice E. Stress in doctors and dentists who teach. Med Educ. 2002;36(6):543-549.

26. Scott I, Sazegar P. Why community physicians teach students (or not): barriers and opportunities for preceptor recruitment. Med Teach. 2006;28(6):563-565.

27. Starr S, Ferguson WJ, Haley H-L, Quirk M. Community preceptors' views of their identities as teachers. Acad Med. 2003;78(8): $820-825$.

28. Starr S, Haley H-L, Mazor KM, Ferguson W, Philbin M, Quirk M. Initial testing of an instrument to measure teacher identity in physicians. Teach Learn Med. 2006;18(2):117-125.

29. Ullian JA, Shore WB, First LR. What did we learn about the impact on community-based faculty? Recommendations for recruitment, retention, and rewards. Acad Med. 2001;76(Suppl 4):S78-S85.

30. Van Ham I, Verhoeven AA, Groenier KH, Groothoff JW, De Haan J. Job satisfaction among general practitioners: a systematic literature review. Eur J Gen Pract. 2006;12(4):174-180.

31. Vath BE, Schneeweiss R, Scott CS. Volunteer physician faculty and the changing face of medicine. West J Med. 2001;174(4): 242-246.

32. Vinson DC, Paden C, Devera-Sales A, Marshall B, Waters EC. Teaching medical students in community-based practices: a national survey of generalist physicians. J Fam Pract. 1997;45(6):487-494.

33. Wilson A, Fraser R, McKinley RK, Preston-Whyte E, Wynn A. Undergraduate teaching in the community: can general practice deliver? Br J Gen Pract. 1996;46(409):457-460.

34. Woolliscroft JO, Harrison RV, Anderson MB. Faculty views of reimbursement changes and clinical training: a survey of award-winning clinical teachers. Teach Learn Med. 2002;14(2):77-86.

35. Wright SM, Beasley BW. Motivating factors for academic physicians within departments of medicine. Mayo Clin Proc. 2004;79(9): 1145-1150.

36. Dodson MC. Motivation and reward factors that affect private physician involvement in an obstetrics and gynecology clerkship. Obstet Gynecol. 1998;92(4 Pt 1):628-633.

37. Kumar A, Loomba D, Rahangdale RY, Kallen DJ. Rewards and incentives for nonsalaried clinical faculty who teach medical students. J Gen Intern Med. 1999;14(6):370-372.

38. Langlois JP. Support of community preceptors: what do they need? Fam Med. 1995;27(10):641-645.

39. Latessa R, Beaty N, Colvin G, Landis S, Janes C. Family medicine community preceptors: different from other physician specialties? Fam Med. 2008;40(2):96-101.

40. Borges NJ, Navarro AM, Grover A, Hoban JD. How, when, and why do physicians choose careers in academic medicine? A literature review. Acad Med. 2010;85(4):680-686.

41. Sturman N. Teaching medical students. Aust Fam Physician. 2011; 40(12):992-995.

42. Thompson C, Dogra N, McKinley R. A survey of general practitioners' opinions and perceived competencies in teaching undergraduate psychiatry. Educ Prim Care. 2010;21(1):20-24.

43. Vinson DC, Paden C. The effect of teaching medical students on private practitioners' workloads. Acad Med. 1994;69(3):237-238.

44. Whiting D. Inappropriate attitudes, fitness to practise and the challenges facing medical educators. J Med Ethics. 2007;33(11):667-670.

45. Connor RA, Hillson SD, Kralewski JE. Association between rural hospitals' residencies and recruitment and retention of physicians. Acad Med. 1994;69(6):483-488.

46. Wigfield A, Guthrie JT, Tonks S, Perencevich KC. Children's motivation for reading : domain specificity and instructional influences. J Educ Res. 1997;97:299-309.

47. Lepper MR, Greene D, Nisbet R. Undermining children's intrinsic interest with extrinsic reward: a test of "overjustification" hypothesis J Pers Soc Psychol. 1973;28:129-137.

48. Lieff SJ. Evolving curriculum design: a novel framework for continuous, timely, and relevant curriculum adaptation in faculty development. Acad Med. 2009;84(1):127-134. 
49. Frohna AZ, Hamstra SJ, Mullan PB, Gruppen LD. Teaching medical education principles and methods to faculty using an active learning approach: the University of Michigan Medical Education Scholars Program. Acad Med. 2006;81(11):975-978.

50. Simpson D, Marcdante K, Morzinski J, et al. Fifteen years of aligning faculty development with primary care clinician-educator roles and academic advancement at the Medical College of Wisconsin. Acad Med. 2006;81(11):945-953.

51. Smith CC, McCormick I, Huang GC. The clinician-educator track: training internal medicine residents as clinician-educators. Acad Med. 2014;89(6):888-891.

52. Jibson MD, Hilty DM, Arlinghaus K, et al. Clinician-educator tracks for residents: three pilot programs. Acad Psychiatry. 2010;34(4): 269-276.
53. Andrew Jay E, Starkman SJ, Pawlina W, Lachman N. Developing medical students as teachers: an anatomy-based student-as-teacher program with emphasis on core teaching competencies. Anat Sci Educ. 2013;6(6):385-392.

54. Krych AJ, March CN, Bryan RE, Peake BJ, Pawlina W, Carmichael SW. Reciprocal peer teaching: students teaching students in the gross anatomy laboratory. Clin Anat. 2005;18(4):296-301.

55. Naeger DM, Conrad M, Nguyen J, Kohi MP, Webb EM. Students teaching students: evaluation of a "near-peer" teaching experience. Acad Radiol. 2013;20(9):1177-1182.

\section{Publish your work in this journal}

Advances in Medical Education and Practice is an international, peerreviewed, open access journal that aims to present and publish research on Medical Education covering medical, dental, nursing and allied health care professional education. The journal covers undergraduate education, postgraduate training and continuing medical education including emerging trends and innovative models linking education, research, and health care services. The manuscript management system is completely online and includes a very quick and fair peer-review system. Visit http://www.dovepress.com/testimonials.php to read rea quotes from published authors.

Submit your manuscript here: http://www.dovepress.com/advances-in-medical-education-and-practice-journal 